\title{
Disease Control and Safety of Belimumab Plus Standard Therapy Over 7 Years in Patients with Systemic Lupus Erythematosus
}

\author{
Ellen M. Ginzler, Daniel J. Wallace, Joan T. Merrill, Richard A. Furie, William Stohl, \\ W. Winn Chatham, Arthur Weinstein, James D. McKay, W. Joseph McCune, Z. John Zhong, \\ William W. Freimuth, and Michelle A. Petri; and the LBSL02/99 Study Group
}

\begin{abstract}
Objective. To evaluate the efficacy/safety of belimumab plus standard therapy in patients $(\mathrm{n}=449)$ with active systemic lupus erythematosus (SLE) treated up to 7 years ( $\mathrm{n}=177$ currently ongoing). Methods. Patients $(\mathrm{n}=345)$ who completed a double-blind, placebo-controlled, 52-week study of belimumab 1, 4, or $10 \mathrm{mg} / \mathrm{kg}$ and 24-week extension of belimumab (placebo switched to $10 \mathrm{mg} / \mathrm{kg}$; belimumab same dose or switched to $10 \mathrm{mg} / \mathrm{kg}$ ) could receive belimumab $10 \mathrm{mg} / \mathrm{kg}$ in an open-label continuation study $(n=296)$. Disease activity was analyzed in patients with active SLE at baseline of the initial study. Biomarker and SLE medication changes were evaluated, and adverse events (AE) were monitored throughout the study.

Results. Total belimumab exposure over 7 years (double-blind and open-label periods): 1746 patient-years. SLE Responder Index (SRI) response rates at Week 52 in autoantibody-positive patients: placebo, 29\%; belimumab, $46 \%$ ( $p<0.05$ ). In the continuation study, $57 \%$ of autoantibody-positive patients had an SRI response by Year 2 and $65 \%$ by Year 7; severe flares occurred in $19 \%$ with placebo and $17 \%$ with belimumab during the first year, with the annual rate declining to $2 \%-9 \%$ during years $2-7$. Anti-dsDNA autoantibodies in patients positive for them at baseline had a progressive decline of $40 \%-60 \%$ from baseline over 2-7 years with belimumab. Corticosteroid use decreased over time with $\geq 50-55 \%$ reduction in median dose during years $5-7$. Serious and overall annual AE rates, including infections, were generally stable or decreased during 7-year treatment.

Conclusion. Disease control and safety profile were maintained in patients with active SLE taking belimumab plus standard therapy for up to 7 years. [ClinicalTrials.gov numbers: NCT00071487 and NCT00583362] (First Release Nov 1 2013; J Rheumatol 2014;41:300-7; doi:10.3899/jrheum.121368)
\end{abstract}

Key Indexing Terms:

BELIMUMAB

SLE RESPONDER INDEX

Systemic lupus erythematosus (SLE) is a chronic autoimmune disorder characterized by autoantibody production

\section{SELENA-SLEDAI \\ SYSTEMIC LUPUS ERYTHEMATOSUS}

and abnormal B lymphocyte function ${ }^{1}$. Despite recent improvements in survival, SLE remains associated with

\begin{abstract}
From the State University of New York (SUNY) Downstate Medical Center, Brooklyn, New York; Cedars-Sinai Medical Center/David Geffen School of Medicine at the University of California at Los Angeles; Oklahoma Medical Research Foundation, Oklahoma City, Oklahoma; North Shore-Long Island Jewish Health System, Lake Success, New York; Los Angeles County + University of Southern California Medical Center and University of Southern California Keck School of Medicine, Los Angeles, California; University of Alabama at Birmingham, Alabama; MedStar Washington Hospital Center, Washington, DC; Oklahoma Center for Arthritis Therapy and Research, Tulsa, Oklahoma; University of Michigan, Ann Arbor, Michigan; Human Genome Sciences Inc., Rockville; Johns Hopkins University School of Medicine, Baltimore, Maryland, USA. Supported by GlaxoSmithKline, Uxbridge, UK; and Human Genome Sciences Inc., Rockville, Maryland, USA.

Drs. Ginzler and Merrill have received consulting fees and research support from GlaxoSmithKline (GSK) and Human Genome Sciences Inc. (HGS).Dr. Wallace has received consulting and speaking fees, and/or honoraria from GSK and HGS. Drs. Furie and Petri have received research or grant support, travel support, and payment for review activities, board membership, and consultancy from GSK and HGS. Dr. Stohl has received clinical trial support from GSK and HGS. Dr. Chatham has received research or grant support and travel support from GSK and HGS.
\end{abstract}

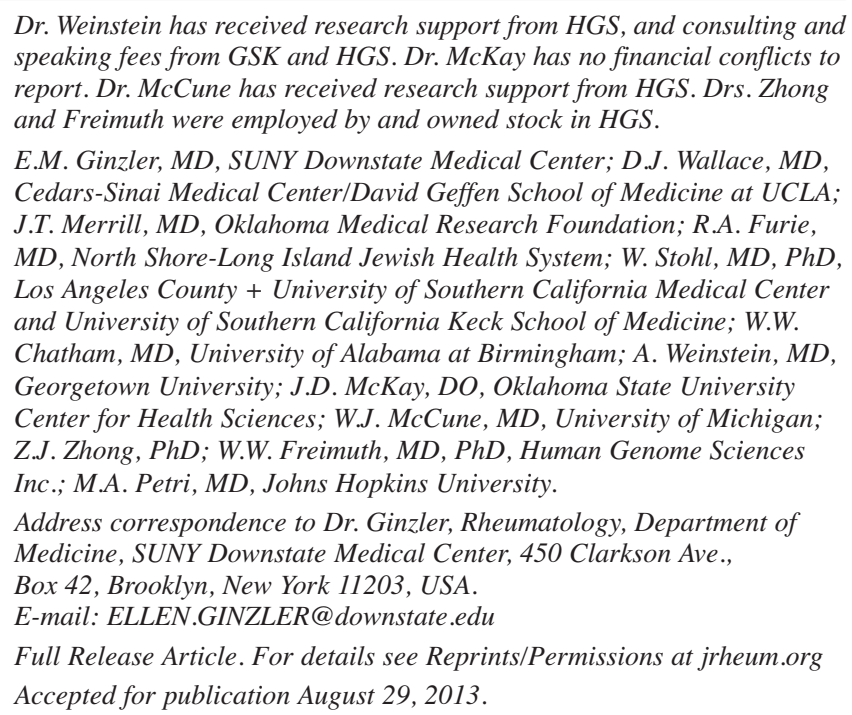

$D r$. Weinstein has received research support from HGS, and consulting and speaking fees from GSK and HGS. Dr. McKay has no financial conflicts to report. Dr. McCune has received research support from HGS. Drs. Zhong and Freimuth were employed by and owned stock in HGS.

E.M. Ginzler, MD, SUNY Downstate Medical Center; D.J. Wallace, MD, Cedars-Sinai Medical Center/David Geffen School of Medicine at UCLA; J.T. Merrill, MD, Oklahoma Medical Research Foundation; R.A. Furie, $M D$, North Shore-Long Island Jewish Health System; W. Stohl, MD, PhD, Los Angeles County + University of Southern California Medical Center and University of Southern California Keck School of Medicine; W.W. Chatham, MD, University of Alabama at Birmingham; A. Weinstein, MD, Georgetown University; J.D. McKay, DO, Oklahoma State University Center for Health Sciences; W.J. McCune, MD, University of Michigan; Z.J. Zhong, PhD; W.W. Freimuth, MD, PhD, Human Genome Sciences Inc.; M.A. Petri, MD, Johns Hopkins University.

Address correspondence to Dr. Ginzler, Rheumatology, Department of Medicine, SUNY Downstate Medical Center, 450 Clarkson Ave., Box 42, Brooklyn, New York 11203, USA.

E-mail: ELLEN.GINZLER@downstate.edu

Full Release Article. For details see Reprints/Permissions at jrheum.org Accepted for publication August 29, 2013. 
significant mortality due partly to an increased risk of death from infection, heart disease, renal disease, complications of severe SLE flares, and certain malignancies (hematologic and lung cancer). Standard SLE therapies may contribute to these risks $2,3,4,5,6$. High-dose corticosteroids are associated with significant morbidity, including osteoporosis, osteonecrosis, metabolic disorders, infections, weight gain, mood disorders, and hyperlipidemia ${ }^{7,8,9}$. Accrual of organ damage in patients with SLE is gradual and variable across organ systems over 15 years, with the greatest damage in the musculoskeletal, ocular, cardiovascular, and neuropsychiatric systems. A significant proportion of damage, both early and accumulated over 15 years, has been attributed to corticosteroids ${ }^{10}$.

Identification of biomarkers to predict the course of SLE and response to therapy is important in managing this disease. B lymphocyte stimulator (BLyS) is overexpressed in patients with SLE and other autoimmune diseases ${ }^{11,12,13,14}$. During 2 years of observation, BLyS levels correlated with changes in SLE disease activity, and with anti-dsDNA antibody titers. Worsening disease activity was predicted by rises in serum BLyS concentrations using the Safety of Estrogen in Lupus Erythematosus National Assessment-SLE Disease Activity Index (SELENA-SLEDAI) and elevated anti-dsDNA antibody titers ${ }^{15}$. Levels of anti-dsDNA and complement (C3 and $\mathrm{C} 4)$ may predict disease activity and exacerbations, and response to treatment $16,17,18,19,20,21$.

Belimumab is a human immunoglobulin (Ig)-G1 $\lambda$ monoclonal antibody that binds to and inhibits soluble human BLyS ${ }^{22,23}$. In a phase II study, a subgroup of autoantibody-positive patients with active SLE at baseline showed improved disease activity [measured by SLE flares, Physician's Global Assessment (PGA), and SELENA-SLEDAI] after 1 year of treatment with belimumab combined with standard therapy compared with placebo plus standard therapy ${ }^{24}$. The drug was generally well tolerated. In 2 pivotal phase III studies, autoantibody-positive patients with SLE who were taking standard therapy were randomized to placebo or belimumab $1 \mathrm{mg} / \mathrm{kg}$ or $10 \mathrm{mg} / \mathrm{kg}^{25,26}$. Both trials met the primary endpoint of a significantly higher response rate at Week 52 in patients treated with belimumab, as assessed by the SLE Responder Index (SRI) ${ }^{27}$, with a safety profile similar to placebo. In addition, greater decreases in autoantibodies and selected B cell subsets, and increases in $\mathrm{C} 3$ and $\mathrm{C} 4$ in patients treated with belimumab versus placebo were observed in the phase II and III trials ${ }^{24,28}$.

In the open-label continuation of the phase II study, belimumab added to standard therapy was generally well tolerated over 4 years $^{29}$. The continuation of the original trial remains ongoing and is the longest general SLE therapy study measuring efficacy and safety. Our report focuses on control of SLE disease activity and safety through 7 years of belimumab treatment.

\section{MATERIALS AND METHODS}

Study design. Entry criteria and design of the double-blind study have been published $^{24}$. Briefly, the phase II study enrolled patients with SLE in a placebo-controlled, randomized 52-week trial of intravenous belimumab 1 $\mathrm{mg} / \mathrm{kg}, 4 \mathrm{mg} / \mathrm{kg}$, and $10 \mathrm{mg} / \mathrm{kg}$ (on days 0,14 , and 28 , and then every 28 days) plus standard therapy, which could include corticosteroids, antimalarials, and immunosuppressant drugs, alone or in combination. Patients who completed the double-blind phase could continue in an uncontrolled, open-label, 24-week extension study, during which those previously receiving placebo were switched to belimumab $10 \mathrm{mg} / \mathrm{kg}$ and those previously receiving belimumab either continued at the same dose $(1,4$, or $10 \mathrm{mg} / \mathrm{kg}$ ) or were switched to $10 \mathrm{mg} / \mathrm{kg}$. Patients who had an improvement in PGA score compared with baseline (day 0) or Week 52 and had no severe SLE flare in the last 30 days of the 24-week extension period could enter an open-label, longterm continuation study, with all patients receiving belimumab $10 \mathrm{mg} / \mathrm{kg}$.

The initial and longterm trials are registered as ClinicalTrials.gov numbers NCT00071487 and NCT00583362, respectively. An institutional review board or ethics committee for each study site reviewed and approved the studies, and all patients gave informed consent before continuing in the longterm protocol.

Efficacy measures. Disease response during the continuation study is assessed every 8 weeks by $\mathrm{PGA}^{30}$ and every 16 weeks by SELENA-SLEDAI ${ }^{31}$, British Isles Lupus Assessment Group $(\text { BILAG })^{32,33,34}$, and SLE Flare Index $(\mathrm{SFI})^{30,31,35}$. Blood samples for evaluation of autoantibody and complement are collected every 16 weeks. Concomitant medication use, including SLE medications (corticosteroids and immunosuppressives), is recorded every 4 weeks.

Efficacy endpoints include percentage change in SELENA-SLEDAI, frequency of 1 new BILAG A or 2 new B scores, frequencies of mild-moderate and severe flares as defined by SFI, and change in corticosteroid use. A posthoc analysis using SRI [defined as $\geq 4$-point reduction in SELENA-SLEDAI, no new BILAG A, and $\leq 1$ new B score, and no worsening (increase of 0.3 ) in PGA score vs baseline] was also performed $^{31}$

Median percentage changes from baseline in $\operatorname{IgG}$ autoantibody (anti-RNA, anti-Smith, anti-dsDNA, and anticardiolipin) and $\operatorname{IgG}, \operatorname{IgA}$, $\operatorname{IgM}$, and $\operatorname{IgE}$ were evaluated, as were normalization of low $\mathrm{C} 3$ and $\mathrm{C} 4$ levels.

Safety measures. Patients were monitored for safety throughout the study. Adverse events (AE) were coded using the Medical Dictionary for Regulatory Activities version 13.1 and graded for severity using the Adverse Event Severity Grading Tables, modified from the US National Institute of Allergy and Infectious Diseases Division of Microbiology and Infectious Disease Adult Toxicity Tables ${ }^{36}$. Safety data monitoring was performed by a sponsor committee that reviews the data semiannually. AE and laboratory data were recorded as reported ${ }^{29}$.

Statistical methods. For the double-blind phase, pooled results of all belimumab doses were compared with placebo during the 52-week double-blind period. For the longterm continuation phase, data were pooled and results presented by 1-year intervals starting from when patients received their first dose of belimumab therapy plus 28 days. The Year 1 interval includes data from 336 patients receiving belimumab 1, 4, or 10 $\mathrm{mg} / \mathrm{kg}$ during the double-blind period and 88 patients formerly on placebo receiving $10 \mathrm{mg} / \mathrm{kg}$ in the continuation phase. Safety and efficacy results in patients initially randomized to placebo were calculated from when they first received belimumab in the second year of the overall trial. In the Year 2 interval, most patients receiving belimumab were receiving $10 \mathrm{mg} / \mathrm{kg} ; 19$ patients continued to receive $1 \mathrm{mg} / \mathrm{kg}$, and 23 received $4 \mathrm{mg} / \mathrm{kg}$ during the 24-week extension phase. In years $3-7$, all patients were receiving belimumab $10 \mathrm{mg} / \mathrm{kg}$. 
Analysis of efficacy was exploratory and limited to patients who were autoantibody-positive (antinuclear antibody titer $\geq 1: 80$ or anti-dsDNA $\geq$ $30 \mathrm{IU} / \mathrm{ml}$ ) at baseline. SRI and PGA were calculated using the last available data point in a given year. For PGA, percentage mean change from baseline was used in the analysis. If a patient discontinued the trial, neither SRI nor PGA was calculated for the years following patient withdrawal. The rates of SFI and BILAG flares were calculated based on the observed flares in a given year. It is worthwhile noting that while the SFI recorded all flares in a given year, the BILAG instrument noted only the new or uncontrolled flares during a 28-day window prior to a visit. To examine the robustness of the efficacy results, similar analyses were performed in the completer population, defined as patients who received $\geq 7$ years of belimumab treatment.
Rates of AE were calculated as number of events/100 patient-years for each 1-year interval. For patients who discontinued during a given interval, 8 weeks of followup safety data were included in the last interval, if available. Safety analyses were performed as reported ${ }^{29}$.

\section{RESULTS}

Patient disposition and baseline demographics. Figure 1 describes the patient disposition for the double-blind, 24-week extension, and longterm continuation periods. Total cumulative patient exposure to belimumab, including that received during the double-blind and open-label phases of the study, was 1746 patient-years.

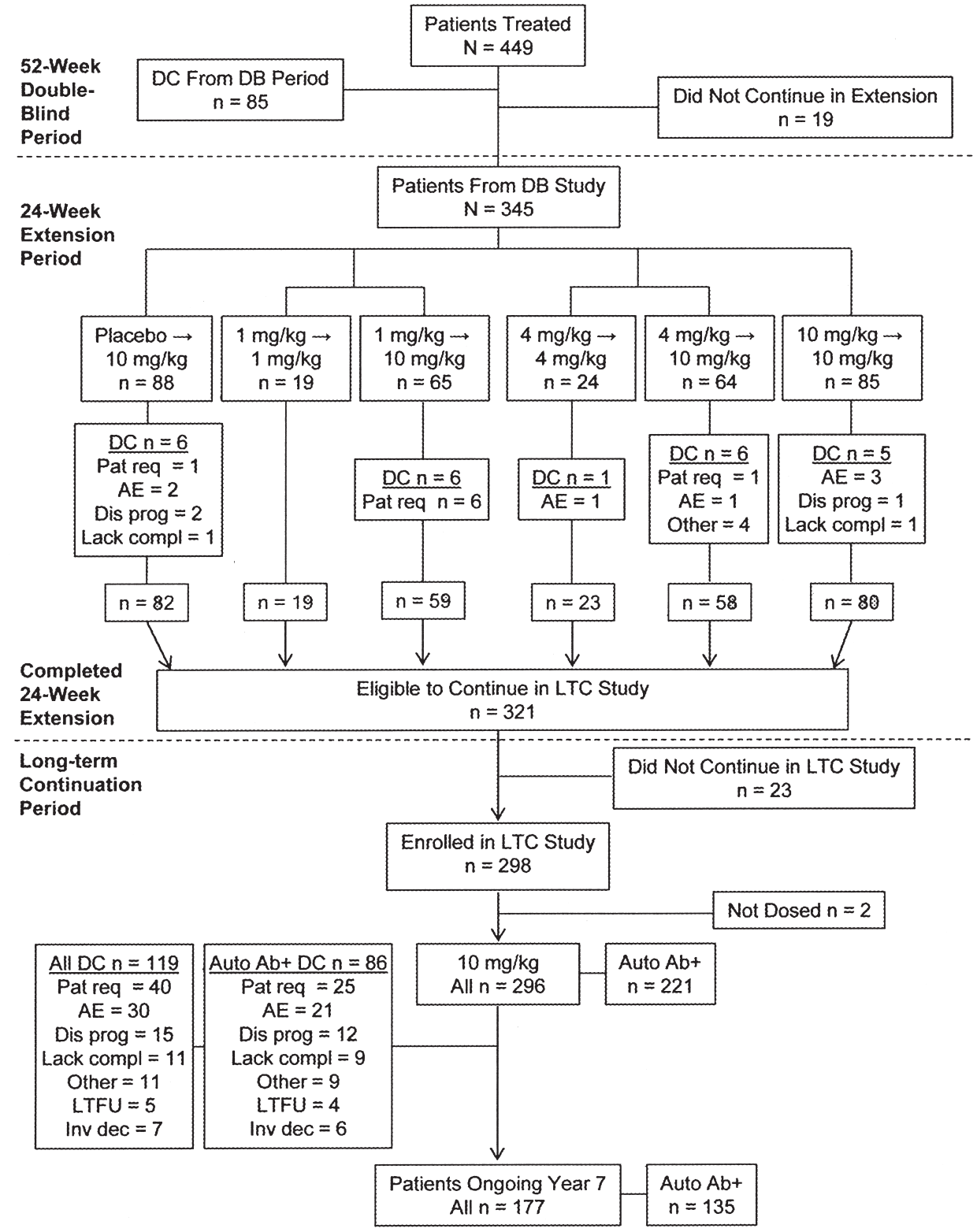

Figure 1. Patient disposition during open-label longterm exposure period. AE: adverse event; Auto Ab+: autoantibody positive; DB: double-blind; DC: discontinuation; Dis prog: disease progression; Inv dec: investigator decision; Lack compl: lack of compliance; LTC: longterm continuation; LTFU: lost to followup; Pat req: patient request. From Wallace DJ, et al. Arthritis Care Res 2009;61:1168-78; and Merrill JT, et al. Arthritis Rheum 2012;64:3364-73. 
Demographic and disease characteristics for patients entering the continuation study and for those who entered and were autoantibody positive at baseline are shown in Table 1. The autoantibody-positive patients entering the extension generally had more serologic activity than the overall study population. The baseline demographics of all patients and autoantibody-positive patients entering the longterm continuation study after 1.5 years in the double-blind and extension phases are similar to the baseline demographics of patients who originally entered the trial ${ }^{24,27}$. Levels of BLyS are not reported because they cannot be accurately measured in the presence of belimumab.

Efficacy endpoints. SRI. The percentage achieving SRI response at Week 52 during the double-blind period in autoantibody-positive patients was $29 \%$ in those receiving placebo versus $46 \%$ in those receiving belimumab ( $p<$ $0.05)^{27}$. In the continuation study, $57 \%$ of patients achieved an SRI response by Year 2, which increased to $65 \%$ by Year 7 (Figure 2A). In addition, a completer analysis showed

Table 1. Demographic and disease characteristics in patients who entered the longterm continuation study.

\begin{tabular}{|c|c|c|}
\hline Characteristic & $\begin{array}{c}\text { All } \\
\mathrm{n}=296\end{array}$ & $\begin{array}{c}\text { Autoantibody Positive, } \\
\qquad \mathrm{n}=221\end{array}$ \\
\hline Women, \% & 93 & 96 \\
\hline Mean age, yrs & 43 & 41 \\
\hline \multicolumn{3}{|l|}{ Ethnicity, \% } \\
\hline White & 72 & 69 \\
\hline Black & 22 & 24 \\
\hline Other & 6 & 7 \\
\hline Mean disease duration, yrs & 8.8 & 9.2 \\
\hline Mean SELENA-SLEDAI score & 9.2 & 9.4 \\
\hline$\geq 1$ BILAG A or $\geq 2$ B scores, $\%$ & 64 & 64 \\
\hline Mean PGA score & 1.4 & 1.4 \\
\hline \multicolumn{3}{|l|}{ Daily prednisone use } \\
\hline All doses, $\%$ & 67 & 72 \\
\hline$>7.5 \mathrm{mg} /$ day, $\%$ & 33 & 38 \\
\hline Average dose, mg/day & $9.9^{*}$ & $10.0^{\dagger}$ \\
\hline Immunosuppressant use, $\%$ & 50 & 52 \\
\hline Azathioprine & 19 & 21 \\
\hline Methotrexate & 17 & 15 \\
\hline MMF & 14 & 17 \\
\hline \multicolumn{3}{|l|}{ Positive autoantibodies, $\%^{\ddagger}$} \\
\hline ANA $^{\S}$ & 73 & 94 \\
\hline Anti-dsDNA & 50 & 67 \\
\hline Anti-RNP & 44 & 57 \\
\hline Anticardiolipin & 26 & 32 \\
\hline Anti-Smith & 19 & 24 \\
\hline Low C4 (<16 mg/dl), \% & 42 & 50 \\
\hline Low C3 $(<90 \mathrm{mg} / \mathrm{dl}), \%$ & 28 & 36 \\
\hline
\end{tabular}

In $* 199$ and ${ }^{\dagger} 159$ patients taking prednisone at baseline; $\$$ in patients with baseline assessment for biomarker; ${ }^{\S}$ antinuclear antibody (ANA) titer $\geq$ 1:80; anti-dsDNA $\geq 30 \mathrm{IU} / \mathrm{ml}$. BILAG: British Isles Lupus Assessment Group; C: complement; MMF: mycophenolate mofetil; PGA: Physician's Global Assessment; SELENA-SLEDAI: Safety of Estrogens in Lupus Erythematosus National Assessment-SLE Disease Activity Index.
$67 \%$ achieved SRI response by Year 2, increasing to $73 \%$ by Year 7 (data not shown). The percentage achieving SRI response among patients with SLE who were seronegative at baseline was similar to that among seropositive patients in the first year (44\% vs $46 \%$, respectively), but was somewhat lower versus seropositive patients in the second year $(48 \%$ vs $57 \%$, respectively). In years 3-7 the percentage of responders in the seronegative population $(58 \%-69 \%)$ was similar to or greater than that in the seropositive population (55\%-65\%; data not shown).

SFI and BILAG flare rates. In autoantibody-positive patients, the percentage of patients experiencing all flares and severe flares, as assessed by SFI, was similar between placebo (85\% all flares and 19\% severe flares, respectively) and belimumab ( $84 \%$ and $17 \%$, respectively) during the double-blind period. During the subsequent years of belimumab exposure in the continuation study, the percentage for all flares and severe flares decreased from $70 \%$ to $40 \%$ and from $7 \%$ to $2 \%$, respectively (Figure $2 \mathrm{~B}$ ). In patients who completed 7 years of study, the rate of any flares $(70.9 \%$ to $44.7 \%$ ) and severe flares (4.9\% to $1.9 \%)$ declined from years 2-7 (data not shown). In seronegative patients, the rate of all flares was similar to that in seropositive patients over 7 years (decreasing from $84.6 \%$ to $39.1 \%$ ). Rate of severe flare was lower for the seronegative group during years 1 and 2 (10.3\% and $4.5 \%$, respectively) and higher over years 3-7 (decreasing from $13.2 \%$ to $6.5 \%$; data not shown), compared with that in the seropositive group. The annual frequency of $\geq 1$ new BILAG A or $\geq 2$ new B scores was highest during the double-blind period in autoantibody-positive patients: $28 \%$ with placebo and $23 \%$ with belimumab. In the continuation study, the BILAG 1A/2B flare rate decreased from $21 \%$ to $8 \%$ during years 2-7 (Figure 2C). In seronegative patients, rates of BILAG $1 \mathrm{~A} / 2 \mathrm{~B}$ flares were somewhat higher in the first year $(31.6 \%)$, and generally declined with some variability from Year $2(18.2 \%)$ to Year 7 (12.8\%; data not shown).

$P G A$ improvement. The mean percentage improvement in PGA in autoantibody-positive patients in the double-blind period was greater with belimumab $(-33 \%)$ than with placebo $(-11 \%)$ at Week $52(\mathrm{p}=0.001)$. With all patients taking belimumab, the PGA mean percentage change improved $(-48 \%)$ in Year 7 (Figure 2D). In seronegative patients, the PGA response was somewhat lower in years 1 and $2(-24.7 \%$ and $-35.0 \%$, respectively), and greater in years $3-7(-49.2 \%$ to $-61.3 \%)$, compared with that in the seropositive group (data not shown).

Complement, immunoglobulin, and autoantibody levels. Autoantibody-positive patients at baseline had normalization rates of low baseline complement levels in the double-blind period of $24 \%$ and $38 \%$ for $\mathrm{C} 4$ in the placebo and belimumab groups, respectively, and of $21 \%$ for $\mathrm{C} 3$ in both groups. The proportions of patients with complement

Personal non-commercial use only. The Journal of Rheumatology Copyright (C) 2014. All rights reserved. 
A

Placebo Belimumab 1, 4, $10 \mathrm{mg} / \mathrm{kg}$ Belimumab $10 \mathrm{mg} / \mathrm{kg}$ only
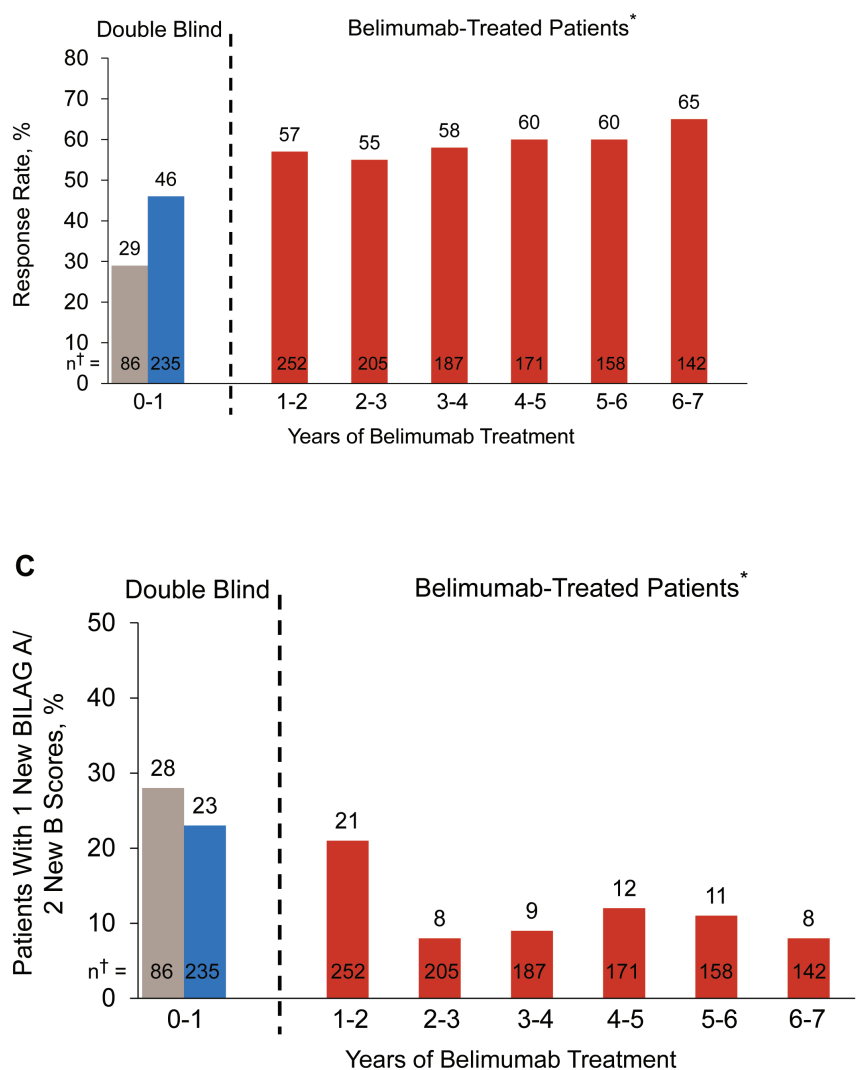

B
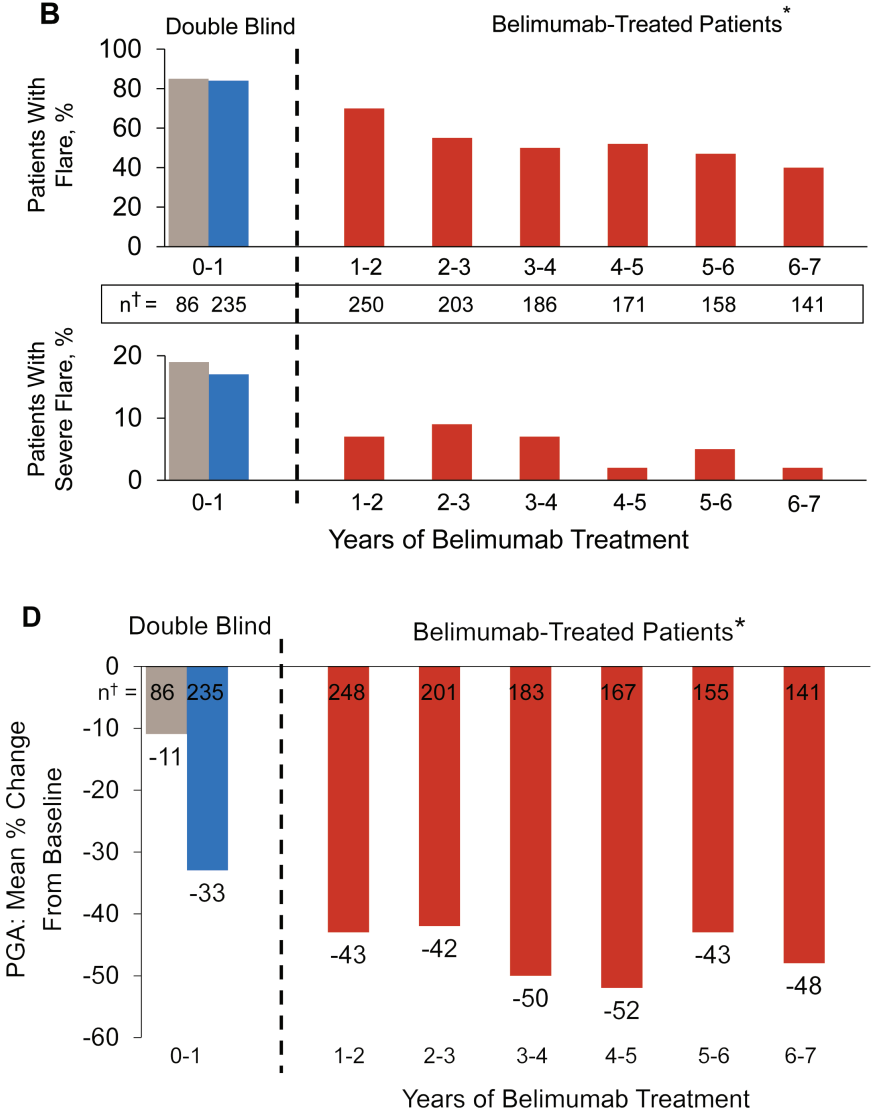

Figure 2. Disease activity over time in autoantibody-positive patients treated with belimumab. (A) Systemic Lupus Erythematosus (SLE) Responder Index response rate; (B) annual frequency of flares measured by modified SLE Flare Index (mild-moderate and/or severe); (C) annual frequency of 1 new British Isles Lupus Assessment Group (BILAG) A or 2 new B scores; (D) mean percentage change in Physician's Global Assessment (PGA) from baseline. *Includes patients originally randomized to belimumab or to placebo and switched to belimumab; patients randomized to placebo are included from first belimumab exposure; data through Year 2 include patients originally randomized to placebo or belimumab 1 or $4 \mathrm{mg} / \mathrm{kg}$ who were switched to $10 \mathrm{mg} / \mathrm{kg}$ at Week 56 . $\dagger$ No. patients with assessments in interval.

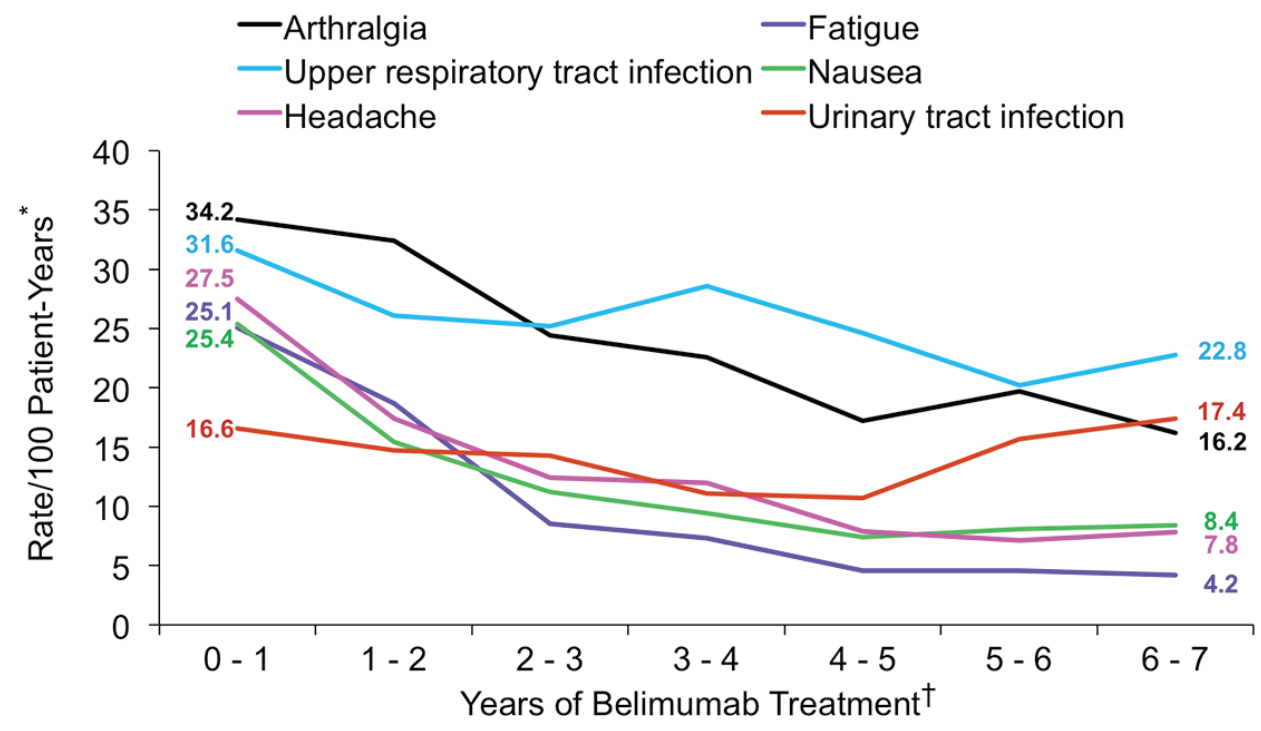

Figure 4. Incidence rate of most common adverse events. $*$ Rate $=(100 \times$ no. patients starting given event in given interval)/(total patient-years in given interval); $\dagger$ Patients switched from placebo to belimumab were included from first belimumab exposure. 
normalization increased to $66 \%$ for $\mathrm{C} 3$ and $71 \%$ for $\mathrm{C} 4$ through 7 years of belimumab exposure (Figure 3A).

Concentrations of $\operatorname{IgG}$ and $\operatorname{IgA}$ were relatively stable during the first 4 years, decreasing modestly during years 5-7 (Figure 3B). Median percentage reductions in IgM and IgE steadily declined over 7 years of exposure. During the 7 years, the frequency of grade 3-4 hypogammaglobulinemia [grade 3: < $400 \mathrm{mg} / \mathrm{dl} ;$ grade $4:<250 \mathrm{mg} / \mathrm{dl}$ (3 cases)] remained low $(1.1 \%-2.6 \%)$ and, when present, was usually observed in patients with a baseline grade 1-3 abnormality. Grade 3-4 hypogammaglobulinemia was not associated with increases in serious infection rates (data not shown). Belimumab was discontinued in 4 patients because of hypogammaglobulinemia: 1 patient each in Year 1 (1

A
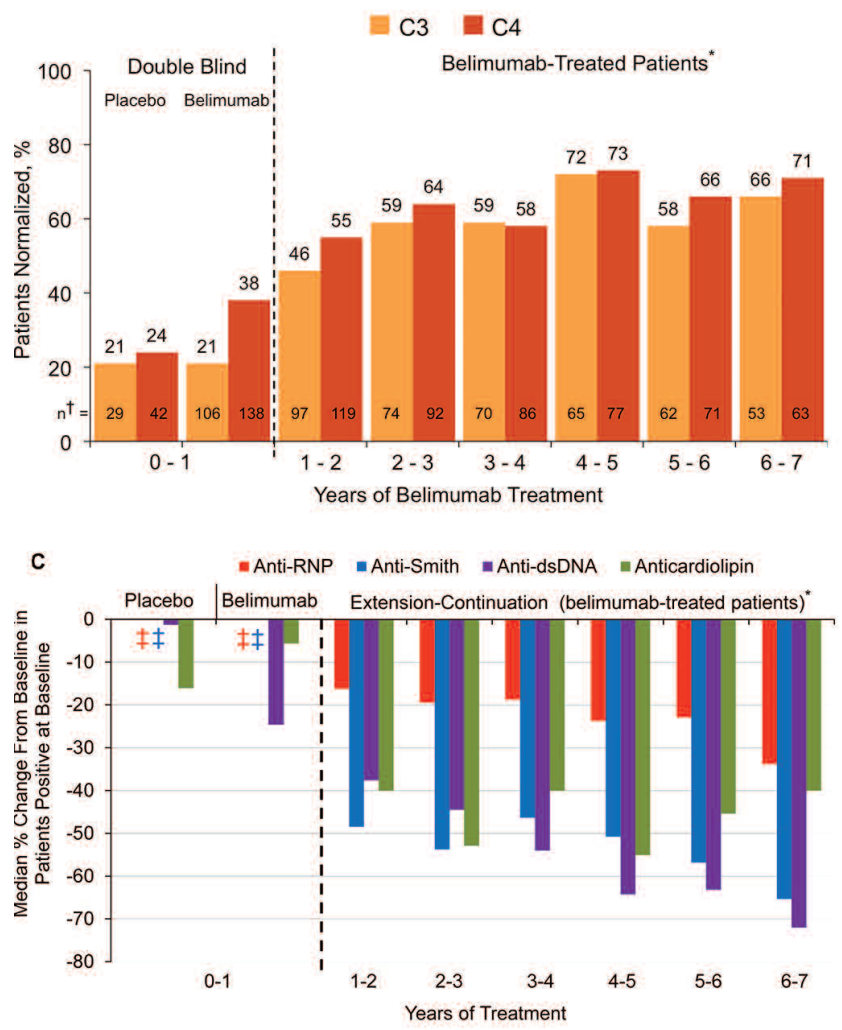

E

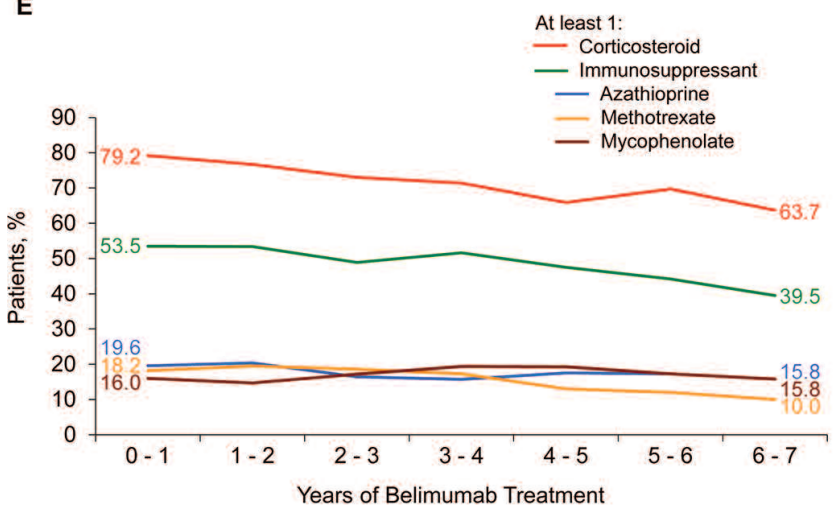

$\mathrm{mg} / \mathrm{kg}$; grades 0-2), Year 5 (grades 2-4), Year 6 (grades $0-2$ ), and Year 7 (grades 2-3). There were also fewer patients who experienced grade 3/4 lymphopenia $(<500$ lymphocytes $/ \mathrm{mm}^{3}$ ) over the 7 years of exposure, decreasing from $22.0 \%$ to $8.4 \%$.

Figure $3 \mathrm{C}$ shows the changes in IgG autoantibody levels for anti-RNP, anti-Smith, anti-dsDNA, and anticardiolipin among patients positive for the respective autoantibody at baseline. These autoantibody levels generally decreased, although with some year-to-year variability.

Corticosteroids and immunosuppressive agents. Of 449 patients entering the double-blind study, 307 (68\%) were taking corticosteroids at baseline. The corticosteroid dose had decreased by $25 \%$ at 2 years of belimumab exposure

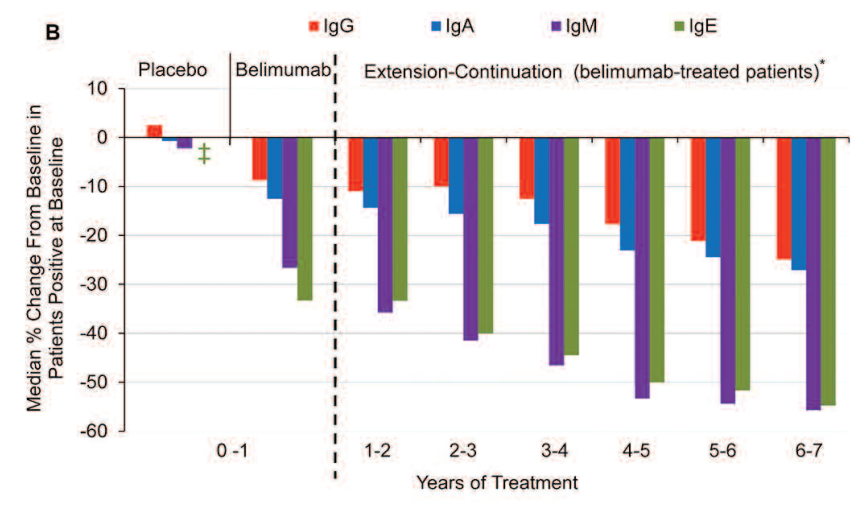

D

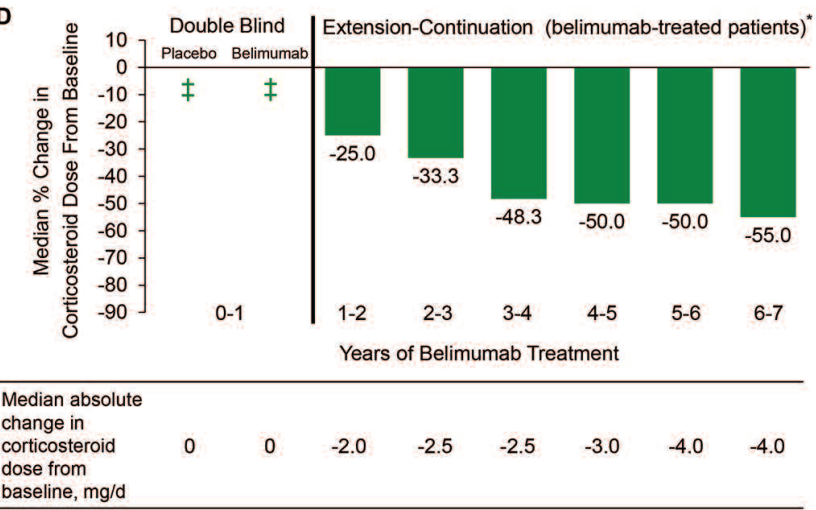

Figure 3. Changes in serologic and medication use in patients treated with belimumab over time. (A) Complement (C3/C4) normalization; (B) changes in immunoglobulin (Ig) isotypes; (C) changes in IgG autoantibody levels in patients positive at baseline; (D) changes in corticosteroid dose; and (E) proportions of patients using corticosteroids and immunosuppressants. Corticosteroid use was among the 283 patients treated with belimumab taking corticosteroids at baseline. Data are based on last available 30-day average within given 1-year interval. *Patients switched from placebo to belimumab are included from first belimumab exposure. $\uparrow$ No. patients with assessments in interval; $¥$ Median percentage change of 0 . 
and by $55 \%$ at 7 years, with corresponding median absolute reductions of 2.0 and $4.0 \mathrm{mg} /$ day (Figure 3D). The proportion of patients who increased their dose of prednisone compared with the previous interval was relatively constant, between $13.2 \%$ and $20.0 \%$ over years 2-7 (data not shown). The proportion of patients who increased their prednisone dose with a mild-moderate or severe SFI flare was $34.9 \%$ in the first year (the highest percentage of severe flares was also observed in this year), and declined to $21.9 \%$ in Year 7 (data not shown). During the study period, there was a gradual decline in the proportion of patients using corticosteroids from $79.2 \%$ to $63.7 \%$ (Figure 3E). In patients who completed 7 years of the study, corticosteroid use decreased by 33\% at Year 2 to $60 \%$ at Year 7 and the proportion of patient corticosteroid use declined from $73.9 \%$ at Year 2 to $65.2 \%$ at Year 7 (data not shown). The proportion of patients taking any immunosuppressants remained constant in the first 4 years, but gradually declined in years 5-7 (baseline 53.5\%-39.5\% in year 7). This decline was particularly evident with methotrexate (baseline $18.2 \%-10.0 \%$ in Year 7). The proportion of patients who added a new immunosuppressant in 1 interval compared with a previous interval was small $(0.5 \%-2.8 \%)$, relatively constant, and $<1.0 \%$ of patients in years 5-7 (data not shown).

Summary of adverse events. The overall incidence rates of $\mathrm{AE}$ were determined on an annual basis and either remained stable or declined through 7 years of belimumab exposure (Table 2). Similar to the first 4 years, mild-moderate infections were the most common AE reported in years 5-7, with upper respiratory tract infections predominating (Figure $4)^{29}$. The serious AE (SAE) of highest incidence (5 patients in any year) were cellulitis, transient ischemic attack, and pneumonia, with rates generally declining over time (data not shown for years 5-7). The most common AE (number of patients) associated with discontinuations over 7 years were malignancies (9), infections (7), skin disorders (6), respiratory problems (5), and decreased $\mathrm{IgG} /$ hypogammaglobulinemia (4). These AE were generally distributed over 7 years, except that $4 / 6$ in skin occurred in the first year and $3 / 4$ had decreased $\operatorname{IgG}$, one each, during years 5-7.

Deaths. Seven deaths occurred during 7 years of belimumab exposure, with an incidence rate of $0.4 / 100$ patient-years (95\% CI 0.16-0.83). The 5 deaths through Year 4 have been reported $^{29}$. No deaths were reported during years 5 and 6 , and 2 deaths occurred in Year 7. One patient, who had surgery for small bowel ischemia and volvulus, and developed worsening respiratory status postoperatively that did not improve despite mechanical and pharmacologic intervention, died of acute respiratory distress syndrome 3 months after the last dose of belimumab. The second patient died of respiratory failure of unknown cause 4 months after the last dose of belimumab. This patient had a recent history of discitis and osteomyelitis of the thoracic spine and aspiration pneumonia. Neither of these deaths was considered related to belimumab by the investigator.

Infusion reactions. Rates of infusion reactions, including hypersensitivity reactions, peaked in Year 1; the rate decreased to 1.2/100 patient-years by Year 7 (Table 2). Two severe and/or serious infusion reactions occurred in the first 4 years, and none occurred in years 5-7 (Table 2). Hypersensitivity reactions were observed only in the first year $^{29}$.

Infections. Infection rates generally decreased over 7 years (Table 2). The rate of serious and/or severe infections peaked in Year 1 (8.3/100 patient-years) and declined in

Table 2. Adverse event incidence (rate/100 patient-years) in patients treated with belimumab*

\begin{tabular}{|c|c|c|c|c|c|c|c|}
\hline Interval (year) & $\begin{array}{l}1(0-1) \\
\mathrm{n}=424\end{array}$ & $\begin{array}{l}2(1-2) \\
n=339\end{array}$ & $\begin{array}{l}3(2-3) \\
n=274\end{array}$ & $\begin{array}{l}4(3-4) \\
n=248\end{array}$ & $\begin{array}{l}5(4-5) \\
\mathrm{n}=223\end{array}$ & $\begin{array}{l}6(5-6) \\
n=208\end{array}$ & $\begin{array}{l}7(6-7) \\
n=190\end{array}$ \\
\hline Patient-years, no. & 374.0 & 299.1 & 258.1 & 234.2 & 215.8 & 197.6 & 167.0 \\
\hline Serious AE & $70(18.7)$ & $52(17.4)$ & $49(19.0)$ & $31(13.2)$ & $41(19.0)$ & $32(16.2)$ & $30(18.0)$ \\
\hline Discontinuations due to $\mathrm{AE}$ & $24(6.4)$ & $8(2.7)$ & $5(1.9)$ & $8(3.4)$ & $6(2.8)$ & $6(3.0)$ & $5(3.0)$ \\
\hline Overall infections & $313(83.7)$ & $237(79.2)$ & $192(74.4)$ & $181(77.3)$ & $145(67.2)$ & $126(63.8)$ & $128(76.6)$ \\
\hline Serious & 0 & 0 & $1(0.4)$ & 0 & 0 & 0 & 0 \\
\hline Malignancies $\ddagger$ & $1(0.3)$ & $5(1.7)$ & $3(1.2)$ & $4(1.7)$ & $4(1.9)$ & $5(2.5)$ & $2(1.2)$ \\
\hline Mortality & $3^{\S}(0.8)$ & 0 & $1(0.4)$ & $1(0.4)$ & 0 & 0 & $2(1.2)$ \\
\hline
\end{tabular}

\footnotetext{
* Data presented as no. of patients with AE (no./100 patient-yrs) unless specified; based on no. of patients remaining on study at end of each 1-year interval; $\dagger$ infusion reactions included $>160$ MedDRA preferred terms (e.g., erythema, flushing, rash, urticaria) occurring on day of infusion with duration of $\leq 7$ days; hypersensitivity reactions were defined as following MedDRA preferred terms that started on day of infusion (regardless of AE duration): anaphylactic reaction, anaphylactic shock, anaphylactoid reaction, anaphylactoid shock, angioedema, drug hypersensitivity, hypersensitivity, and tachyphylaxis; $¥$ includes definite and unspecified solid organ, skin melanoma and non-skin melanoma, and hematologic malignancies; ${ }^{\S}$ in the Year 1 interval, 2 belimumab patients died during the 52-week, double-blind period; and 1 patient treated with placebo during double-blind period and subsequently switched to belimumab 10 $\mathrm{mg} / \mathrm{kg}$ died after $\sim 232$ days of belimumab exposure. AE: adverse events; MedDRA: Medical Dictionary for Regulatory Activities.
}

Personal non-commercial use only. The Journal of Rheumatology Copyright (c) 2014. All rights reserved. 
years 2-7 (6.0-3.6/100 patient-years). Individual serious infections occurred at a rate $\leq 2 / 100$ patient-years in any yearly interval, and no specific infection type predominated. Two opportunistic infections, both in Year 4, were reported $^{29}$; none were reported in years 5-7.

Malignancies. Malignancies (excluding nonmelanoma skin cancers) occurred at a rate of $0.7 / 100$ patient-years $(95 \% \mathrm{CI}$ 0.4-1.27) during the 7 years. In the first 4 years of exposure, 2 solid organ cancers, 2 hematologic malignancies, and 7 nonmelanoma skin cancers were reported ${ }^{29}$. In years $5-7$, seven solid organ cancers [including breast cancer/breast cancer in situ ( 1 each in years 5, 6, and 7), colon cancer (Year 5), malignant melanoma (Year 5), renal cell carcinoma (Year 5), and lung neoplasm (Year 6)] were reported. Four nonmelanoma skin cancers were reported in years 5-7: three squamous cell carcinomas ( 2 in Year 6, and 1 in Year 7) and 1 basal cell carcinoma (Year 6); the average age of these patients was $\sim 59$ years.

\section{DISCUSSION}

Our report describes the efficacy and safety data in patients with SLE exposed to belimumab and standard SLE therapy over 7 years. Patients initially entered the trial with moderate-severe SLE disease activity. Standard therapy was continued as needed alongside belimumab, with no therapeutic modifications mandated to physicians or patients. This is the longest reporting period from an ongoing trial of a biologic agent for patients with SLE. Over 7 years, there was a low discontinuation rate, with malignancy and infections the most common causes. The low frequency of $\mathrm{AE}$ was likely attributed to a sustained reduction in disease activity as measured by SRI or PGA, low rates of all flares or severe SLE flares, and improvement in serologic activity. The annual rates of all AE per 100 patient-years, including SAE, infections, hypersensitivity reactions, malignancy, and deaths, generally remained stable or declined over 7 years. However, the occurrence of specific types of $\mathrm{AE}$ or $\mathrm{SAE}$ varied over time, so vigilance should be maintained for new SAE and new or renewed severe SLE disease manifestations over time.

The mortality rate of $0.4 / 100$ patient-years observed in the longterm continuation study of belimumab is below the rate of 1.63 reported for $\mathrm{SLE}^{37}$, although the historical rate may be an overestimate given decreases in SLE mortality rates seen over time, and because patients in a clinical trial may be followed and monitored differently from those in a practice setting ${ }^{38}$. Notably, there was no apparent increased risk of mortality associated with belimumab treatment over 7 years. The malignancies (excluding nonmelanoma skin cancer) observed in this study are consistent with those expected in an SLE population largely composed of women, and the malignancy rate $(0.7 / 100$ patient-years) is similar to the background rate reported in patients with SLE $(0.53 / 100$ patient-years $)^{2}$. In the continuation study, serious infusion and hypersensitivity reactions and opportunistic infections were rare. Hypogammaglobulinemia was infrequent and led to discontinuation of belimumab in 4 patients over 7 years. During 7 years of belimumab treatment, no new safety concerns emerged. The data in this longterm analysis are consistent with the findings in the phase II and III placebo-controlled belimumab trials, i.e., no specific patterns of infections and no increase in the incidence or severity of $\mathrm{AE}^{24,25,26,29}$.

Several novel targeted biological therapies have been studied for the treatment of SLE with the hypothesis that targeted immune modulators may be safer than global immunosuppression, especially regarding serious infections ${ }^{39,40}$. As noted previously, high-dose corticosteroids are associated with significant morbidity ${ }^{7,8,9}$. Corticosteroid use decreased over time, with a 55\% reduction in dose for patients who remained on study for 7 years. In contrast, $13 \%-20 \%$ of patients increased their corticosteroid dose in a given interval compared with a previous interval during the 7-year study. Generally, corticosteroid sparing is likely to be beneficial in the treatment of patients with SLE. The longterm side effects of corticosteroid therapy are well documented, with corticosteroid-related damage found to accumulate with longterm (15-year) therapy in another study ${ }^{10}$. Additionally, in the present study, the overall immunosuppressive agent use was fairly constant over the first 4 years; the proportion of patients taking immunosuppressants declined in years $5-7$. Fewer than $3 \%$ of patients added a new immunosuppressant in an interval during years 2-7 compared with the previous interval.

Autoantibody-positive patients with SLE who were treated with belimumab plus standard therapy had sustained disease control, and decreased and stabilized frequency of all flares and severe flares, over 7 years. The annual rate of severe SFI or BILAG flares after 2 years of belimumab therapy was decreased by $>50 \%$ through 7 years compared with the first year flare rate with placebo. Disease activity reduction as measured by SRI and PGA remained stable following 2-7 years of therapy, and patients who had 7 years of continual belimumab plus standard therapy had similar findings in the completer analysis. The normalization of complement and decreases in autoantibody levels achieved over 7 years are important because these biomarkers have been associated with increased risk of renal disease and severe SLE flares. The reductions in disease activity and flares coincided with improvement in serologic activity and reduction in corticosteroid dose. The small group of seronegative patients had a somewhat lesser response for SRI and PGA in the first and second years of belimumab treatment compared with the response of seropositive patients. During years 3-7, responses were slightly better in the seronegative group than in the seropositive group. With regard to rates of SLE flare, the 2 groups had similar rates of any SFI flare over 7 years. Rates of severe and BILAG

Personal non-commercial use only. The Journal of Rheumatology Copyright (c) 2014. All rights reserved. 
$1 \mathrm{~A} / 2 \mathrm{~B}$ flares in seronegative patients were more variable over time, but usually somewhat higher overall than in seropositive patients over 7 years.

These data have some limitations. The population that entered the longterm continuation study and continued throughout 7 years was potentially enriched with patients who responded to or tolerated belimumab. There was no matched-control group to directly compare the longterm safety and efficacy data. The discontinuation rate due to $\mathrm{AE}$ or infections was low and declined over time.

Although this reflects a survivor bias, the data suggest that most patients avoided major AE with belimumab for $\geq$ 1 year; once they reached the 1-year milestone, the likelihood of continuing to do well for up to 7 years increased. The population who participated in the continuation study had similar demographic and other baseline characteristics to the population enrolled in the double-blind study, addressing the risk of selection bias at the start of the study ${ }^{24}$. In addition, the baseline demographics of the autoantibody-positive patients with SLE were similar to those of the entire study population except for a greater proportion of patients with serologic activity (presence of autoantibodies and/or low $\mathrm{C} 3 / \mathrm{C} 4$ ) at baseline. Finally, all SLE flares and severe flares were collected by SFI any time during the trial, and flares defined at each visit as new BILAG $1 \mathrm{~A} / 2 \mathrm{~B}$ were also recorded. Because the visits were 16 weeks apart in the extension, the reduced frequency of patient assessments for disease activity and flare may have led to underreporting of the actual number of SLE flares, particularly mild flares, which could come and go between visits without being recorded.

These data show that belimumab administered over the long term with standard therapy was generally well tolerated, and sustained disease control was maintained for up to 7 years in patients with active SLE at baseline. These data can provide the benchmark of longterm clinical data to develop more effective and better-tolerated SLE combination therapeutic strategies.

\section{ACKNOWLEDGMENT}

The authors thank Geoff Marx of BioScience Communications, New York, NY, for editorial assistance.

\section{APPENDIX 1}

List of study collaborators. The LBSL02/99 Study Group: Cynthia Aranow, Robert Arthur, John Babich, Eugene Boling, Jeffrey Booth, Richard Brasington, Michael Burnette, Winn Chatham, Eliza Chakravarty, Ann Clarke, John Condemi, Mary Cronin, Carol Danning, Emma Dilorio, Mary Dooley, James Dreyfus, Guy Fiocco, Pamela Freeman, Richard Furie, Mark Genovese, Norman Gaylis, Ellen Ginzler, William Gruhn, Paul Howard, Richard Jimenez, David Karp, Robert Katz, Phillip Kempf, Howard Kenney, Steven Klein, Joel Kremer, Eric Lee, Sam Lim, Stephen Lindsey, Jeffrey Lisse, Raymond Malamet, Susan Manzi, Timothy McAlindon, Angela McCain, W. Joseph McCune, James McKay, Joan T. Merrill, Nilamadhab Mishra, Carter Multz, Michelle Petri, Dianne Petrone, Bryan Pogue, Charles Pritchard, Robert Quinet, Rosalind
Ramsey-Goldman, Violeta Rus, Bruce Samuels, Michael Sayers, Craig Scoville, Alexander Shikhman, Steven Stern, Jon Stevenson, William Stohl, James Trice, Robert Valente, Daniel Wallace, Arthur Weinstein, Michael Weisman, Frank Wellborne, Richard White, and Stanford Wolfe.

\section{REFERENCES}

1. Pisetsky DS. Systemic lupus erythematosus. A. Epidemiology, pathology, and pathogenesis. In: Klippel JH, ed. Primer on the rheumatic diseases. 12th ed. Atlanta, GA: Arthritis Foundation; 2001:329-35.

2. Bernatsky S, Boivin JF, Joseph L, Rajan R, Zoma A, Manzi S, et al. An international cohort study of cancer in systemic lupus erythematosus. Arthritis Rheum 2005;52:1481-90.

3. Bernatsky S, Joseph L, Boivin JF, Gordon C, Urowitz M, Gladman $\mathrm{D}$, et al. The relationship between cancer and medication exposures in systemic lupus erythaematosus: a case-cohort study. Ann Rheum Dis 2008;67:74-9.

4. Cervera R, Khamashta MA, Font J, Sebastiani GD, Gil A, Lavilla P, et al. Morbidity and mortality in systemic lupus erythematosus during a 10-year period: a comparison of early and late manifestations in a cohort of 1,000 patients. Medicine 2003; 82:299-308.

5. Goldblatt F, Chambers S, Rahman A, Isenberg DA. Serious infections in British patients with systemic lupus erythematosus: hospitalisations and mortality. Lupus 2009;18:682-9.

6. Roman MJ, Shanker BA, Davis A, Lockshin MD, Sammaritano L, Simantov R, et al. Prevalence and correlates of accelerated atherosclerosis in systemic lupus erythematosus. N Engl J Med 2003;349:2399-406.

7. Petri M, Purvey S, Fang H, Magder LS. Predictors of organ damage in systemic lupus erythematosus: the Hopkins Lupus Cohort. Arthritis Rheum 2012;64:4021-8.

8. Thamer M, Hernán MA, Zhang Y, Cotter D, Petri M. Prednisone, lupus activity, and permanent organ damage. J Rheumatol 2009;36:560-4.

9. Zonana-Nacach A, Barr SG, Magder LS, Petri M. Damage in systemic lupus erythematosus and its association with corticosteroids. Arthritis Rheum 2000;43:1801-8.

10. Gladman DD, Urowitz MD, Rahman P, Ibañez D, Tam LS. Accrual of organ damage over time in patients with systemic lupus erythematosus. J Rheumatol 2003;30:1955-9.

11. Cheema GS, Roschke V, Hilbert DM, Stohl W. Elevated serum B lymphocyte stimulator levels in patients with systemic immune-based rheumatic diseases. Arthritis Rheum 2001;44:1313-9.

12. Groom J, Kalled SL, Cutler AH, Olson C, Woodcock SA, Schneider $\mathrm{P}$, et al. Association of BAFF/BLyS overexpression and altered B cell differentiation with Sjögren's syndrome. J Clin Invest 2002;109:59-68.

13. Mariette X, Roux S, Zhang J, Bengoufa D, Lavie F, Zhou T, et al. The level of BLyS (BAFF) correlates with the titre of autoantibodies in human Sjögren's syndrome. Ann Rheum Dis 2003;62:168-71.

14. Zhang J, Roschke V, Baker KP, Wang Z, Alarcón GS, Fessler BJ, et al. Cutting edge: a role for B lymphocyte stimulator in systemic lupus erythematosus. J Immunol 2001;166:6-10.

15. Petri M, Stohl W, Chatham W, McCune WJ, Chevrier M, Ryel J, et al. Association of plasma B lymphocyte stimulator levels and disease activity in systemic lupus erythematosus. Arthritis Rheum 2008;58:2453-9.

16. Hahn BH, McMahon MA, Wilkinson A, Wallace WD, Daikh DI, Fitzgerald JD, et al. American College of Rheumatology guidelines for screening, treatment, and management of lupus nephritis. Arthritis Care Res 2012;64:797-808.

17. Petri M, Singh S, Tesfasyone H, Malik A. Prevalence of flare and influence of demographic and serologic factors on flare risk in systemic lupus erythematosus: a prospective study. J Rheumatol

Personal non-commercial use only. The Journal of Rheumatology Copyright @ 2014 . All rights reserved. 
2009;36:2476-80.

18. Schmajuk G, Yazdany J. Drug monitoring in systemic lupus erythematosus: a systematic review. Semin Arthritis Rheum 2011;40:559-75.

19. Schur PH, Sandson J. Immunologic factors and clinical activity in systemic lupus erythematosus. N Engl J Med 1968;278:533-8.

20. ter Borg EJ, Horst G, Hummel EJ, Limburg PC, Kallenberg CG. Measurement of increases in anti-double-stranded DNA antibody levels as a predictor of disease exacerbation in systemic lupus erythematosus. A long-term, prospective study. Arthritis Rheum 1990;33:634-43.

21. Tseng CE, Buyon JP, Kim M, Belmont HM, Mackay M, Diamond $\mathrm{B}$, et al. The effect of moderate-dose corticosteroids in preventing severe flares in patients with serologically active, but clinically stable, systemic lupus erythematosus: findings of a prospective, randomized, double-blind, placebo-controlled trial. Arthritis Rheum 2006;54:3623-32.

22. Baker KP, Edwards BM, Main SH, Choi GH, Wager RE, Halpern WG, et al. Generation and characterization of LymphoStat-B, a human monoclonal antibody that antagonizes the bioactivities of $\mathrm{B}$ lymphocyte stimulator. Arthritis Rheum 2003;48:3253-65.

23. Halpern WG, Lappin P, Zanardi T, Cai W, Corcoran M, Zhong J, et al. Chronic administration of belimumab, a BLyS antagonist, decreases tissue and peripheral blood B-lymphocyte populations in cynomolgus monkeys: pharmacokinetic, pharmacodynamic, and toxicologic effects. Toxicol Sci 2006;91:586-99.

24. Wallace DJ, Stohl W, Furie RA, Lisse JR, McKay JD, Merrill JT, et al. A phase II, randomized, double-blind, placebo-controlled, dose-ranging study of belimumab in patients with active systemic lupus erythematosus. Arthritis Rheum 2009;61:1168-78.

25. Furie R, Petri M, Zamani O, Cervera R, Wallace DJ, Tegzová D, et al. A phase III, randomized, placebo-controlled study of belimumab, a monoclonal antibody that inhibits B lymphocyte stimulator, in patients with systemic lupus erythematosus. Arthritis Rheum 2011;63:3918-30.

26. Navarra SV, Guzman RM, Gallacher AE, Hall S, Levy RA, Jimenez $\mathrm{RE}$, et al. Efficacy and safety of belimumab in patients with active systemic lupus erythematosus: a randomised, placebo-controlled, phase 3 trial. Lancet 2011;377:721-31.

27. Furie RA, Petri MA, Wallace DJ, Ginzler EM, Merrill JT, Stohl W, et al. Novel evidence-based systemic lupus erythematosus responder index. Arthritis Rheum 2009;61:1143-51.
28. Stohl W, Hiepe F, Latinis KM, Thomas M, Scheinberg MA, Clarke A, et al. Belimumab reduces autoantibodies, normalizes low complement levels, and reduces select B cell populations in patients with systemic lupus erythematosus. Arthritis Rheum 2012; 64:2328-37.

29. Merrill JT, Ginzler EM, Wallace DJ, McKay JD, Lisse JR, Aranow C, et al; LBSL02/99 Study Group. Long-term safety profile of belimumab plus standard therapy in patients with systemic lupus erythematosus. Arthritis Rheum 2012;64:3364-73.

30. Petri M, Buyon J, Kim M. Classification and definition of major flares in SLE clinical trials. Lupus 1999;8:685-91.

31. Petri M, Kim MY, Kalunian KC, Grossman J, Hahn BH, Sammaritano LR, et al. Combined oral contraceptives in women with systemic lupus erythematosus. N Engl J Med 2005;353:2550-8.

32. Gordon C, Sutcliffe N, Skan J, Stoll T, Isenberg DA. Definition and treatment of lupus flares measured by the BILAG index. Rheumatology 2003;42:1372-9.

33. Hay EM, Bacon PA, Gordon C, Isenberg DA, Maddison P, Snaith ML, et al. The BILAG index: a reliable and valid instrument for measuring clinical disease activity in systemic lupus erythematosus. QJ Med 1993;86:447-58.

34. Isenberg DA, Gordon C; BILAG Group. British Isles Lupus Assessment Group. From BILAG to BLIPS: disease activity assessment in lupus past, present and future. Lupus 2000;9:651-4.

35. Buyon JP, Petri MA, Kim MY, Kalunian KC, Grossman J, Hahn $\mathrm{BH}$, et al. The effect of combined estrogen and progesterone hormone replacement therapy on disease activity in systemic lupus erythematosus: a randomized trial. Ann Intern Med 2005;142:953-62.

36. National Institute of Allergy and Infectious Diseases. Toxicity Tables. Division of Microbiology and Infectious Diseases, 2001. [Internet. Accessed Sept 10, 2013]. Available from: http://www.niaid.nih.gov/labsandresources/resources/dmidclinrsrch/ pages/toxtables.aspx

37. Bernatsky S, Boivin JF, Joseph L, Manzi S, Ginzler E, Gladman DD, et al. Mortality in systemic lupus erythematosus. Arthritis Rheum 2006;54:2550-7.

38. Ippolito A, Petri M. An update on mortality in systemic lupus erythematosus. Clin Exp Rheumatol 2008;26 Suppl 51:S72-9.

39. Karim MY, Pisoni CN, Khamashta MA. Update on immunotherapy for systemic lupus erythematosus - What's hot and what's not! Rheumatology 2009;48:332-41.

40. Lateef A, Petri M. Biologics in the treatment of systemic lupus erythematosus. Curr Opin Rheumatol 2010;22:504-9. 